\title{
Promotion of colorectal neoplasia in experimental murine ulcerative colitis
}

\author{
I Okayasu, T Ohkusa, K Kajiura, J Kanno, S Sakamoto
}

\begin{abstract}
Background-The mechanisms underlying the frequent development of colorectal carcinomas in patients with ulcerative colitis are still unknown.

Aims-To evaluate whether mucosal necrosis and regeneration act as enhancing or promoting factors in colorectal tumorigenesis, development of multiple colorectal tumours was studied in a murine model of ulcerative colitis with azoxymethane pretreatment.
\end{abstract}

Methods-Periods of chronic ulcerative colitis in mice were induced by three repeated administrations of $3 \%$ dextran sulphate sodium subsequent to a single azoxymethane pretreatment, to give conditions similar to the clinically observed active and remission phases.

Results-In the chronic colitis group with carcinogen exposure, multiple mucosal tumours $(10.5 / \mathrm{mouse})$ developed in the colorectum. This occurred primarily on the left side of the large intestine or transverse colon, the sites of the most severe colitic injury. The observed lesions were high grade dysplasias and invasive adenocarcinomas. Increased cell proliferation was evidenced by high uptake of bromodeoxyuridine, and increased activities of thymidylate synthetase and thymidine kinase. No tumours were induced in the control groups with azoxymethane pretreatment or chronic colitis alone.

Conclusions-Repeated mucosal erosion with necrosis and regeneration is critical for the development of colorectal tumours in this experimental colitis system.

(Gut 1996; 39: 87-92)

Keywords: ulcerative colitis, colorectal tumour, experimental colitis, dextran sulphate sodium.

An increased incidence of colorectal cancer occurs in patients with ulcerative colitis, ${ }^{1-4}$ and a standard clinicopathological cancer surveillance system has recently been introduced in North America, Europe, and Japan to monitor this problem. ${ }^{5}$ However, the pathogenetic background to the frequent development of colorectal cancer in patients with chronic ulcerative colitis has yet to be established. We earlier reported the occurrence of dysplasia and carcinoma in hamsters after longstanding ulcerative colitis caused by longterm treatment with dextran sulphate sodium (DSS). ${ }^{6}$ Clinically, however, subjects with chronic ulcerative colitis typically display a recurrence-remission cycle, manifesting periods of mucosal ulceration accompanied by necrosis and regeneration of the colonic mucosa. This process of repeated damage and repair thus seems to increase the susceptibility of mucosal epithelia for colorectal tumour development. ${ }^{4}$ Accordingly, it can be supposed that the state of chronic ulcerative colitis acts as a promoter of neoplasia in the colon.

To test this hypothesis, we attempted to induce colon cancer in a reliable murine model of experimental chronic ulcerative colitis caused by repeated administrations of DSS solution. ${ }^{7}$ The features of the induced colitis in this model are very similar to those seen in human patients in terms of both clinical and histopathological characteristics, including diarrhoea, occult blood, melaena, mucosal inflammatory cell infiltration, crypt abscess formation, and mucosal erosion. It was suggested that DSS administration results in inappropriate macrophage and lymphocyte functions, ${ }^{89}$ changes in the luminal bacteria, ${ }^{7}$ and toxic effects on the colonic-epithelium, resulting in ulcerative colitis. ${ }^{10}$ This study was conducted to establish any enhancing effect of chronic ulcerative colitis on colorectal carcinoma development.

\section{Methods}

\section{Mice}

A total of 85 specific pathogen free CBA/J female mice (Charles River, Kanagawa, Japan), 6 weeks of age, were housed at our Animal Laboratory Centre prior to experimental inductions of ulcerative colitis and colorectal tumours. They were kept under standard laboratory conditions and permitted free access to animal chow (CE-2, Nippon Clear, Tokyo, Japan) and DSS-supplemented or normal drinking water.

Administration of azoxymethane

Mice were injected intraperitoneally with $7 \cdot 4$ $\mathrm{mg} / \mathrm{kg}$ azoxymethane (Ash Stevens, Detroit, $\mathrm{MI})$ at the age of 7 weeks.

Administration of DSS

Mice were given distilled water containing 0 or $3 \%$ (wt/vol) synthetic DSS (mol wt 54000 ; Meitoh Sangyo, Tokyo) ad libitum under the regimen established for the experiment.

Protocol for induction of colorectal tumours After intraperitoneal pretreatment with azoxymethane $(7 \cdot 4 \mathrm{mg} / \mathrm{kg})$, the animals were
Correspondence to: Dr I Okayasu, Department of Pathology, Kitasato Medicine, Kitasato 1-15-1, Jagam.

Accepted for publication 31 January 1996 

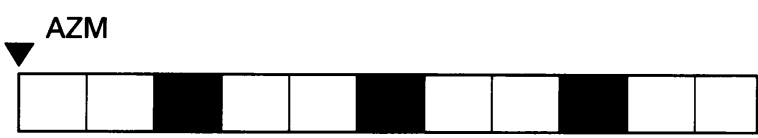

Group B (DW)
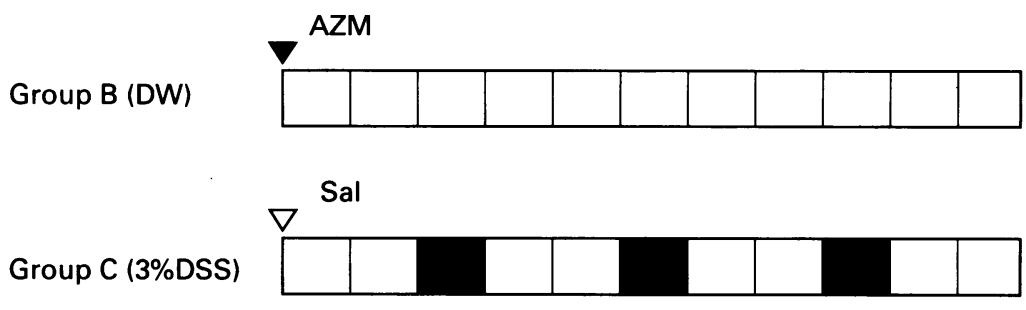

Sal

Group D (DW)

Figure 1: The protocol used for inducing colorectal tumours in association with chronic ulcerative colitis in mice by a single azoxymethane pretreatment. Azoxymethane (AZM; $7.4 \mathrm{mg} / \mathrm{kg}$ ) or saline was injected intraperitoneally at seven weeks of age. Shaded squares represent periods of administration of distilled water containing $3 \%$ DSS. Open squares are intervals of administration of distilled water (DW). Each square represents a period of seven days. Solid and open arrows show azoxymethane (AZM) and saline (Sal) pretreatment, respectively. inflammatory cell infiltration or crypt abscess formation; 3, mucosal ulceration, or five or more foci of gland loss with inflammatory cell infiltration; 4, two or more areas of mucosal ulceration.

\section{In vivo bromodeoxyuridine labelling and} histological examination

One hour before death, $40 \mathrm{mg} / \mathrm{kg}$ bromodeoxyuridine (BrdU; Sigma Chemical, St Louis, MO) were administered intraperitoneally. After 48 hours' fixation in a $10 \%$ formalin solution ( $\mathrm{pH} 7 \cdot 4)$, all colons were sectioned, dehydrated, and embedded in paraffin wax. To identify BrdU labelled nuclei, immunohistochemistry was performed with the streptavidin biotin-peroxidase method ${ }^{13}$ using a Histofine SAB-PO kit (Nichirei, Tokyo, Japan). In brief, deparaffinised sections ( $4 \mu \mathrm{m}$ in thickness) were treated with $2 \mathrm{~N} \mathrm{HCl}$ for 60 minutes, treated twice with $0 \cdot 1 \mathrm{M}$ borate buffer $(\mathrm{pH}$ 8.5) for five minutes, washed, and then incubated with 20 -fold diluted mouse monoclonal antibody against BrdU (DAKO, Copenhagen, Denmark) for one hour at room temperature. After exposure to biotinylated rabbit antimouse immunoglobulin $\mathrm{G}$ for 40 minutes, the sections were incubated with peroxidaselabelled streptavidine for 40 minutes. The diaminobenzidine reaction was performed for colour development. Faint nuclear counterstaining was achieved with Meyer's haematoxylin solution. or maintained as untreated controls (Fig 1) The total amounts of administered DSS in groups A (3.07 $\mathrm{g} /$ mouse), and C (3.07 $\mathrm{g} /$ mouse) were equal. Surviving animals were killed under ether anaesthesia at the end of week 11.

All polypoid or flat elevated lesions that developed were examined macroscopically and histopathologically confirmed by observation of haematoxylin and eosin stained paraffin wax sections.

\section{Observation of colitis}

Faecal examination of colitis animals was conducted as previously described. ${ }^{7}$ Briefly, using the orthotolidine and guajac method, ${ }^{11}$ occult blood in the faeces was evaluated by means of test papers (Occult blood slides; Shionogi Pharmaceutical, Osaka, Japan).

\section{Morphological analysis}

All analyses were performed in a blind fashion according to the method described previously. ${ }^{7}$ After preparations of colonic walls adhering to thick filter paper (Advantec; Toyo Roshi, Tokyo, Japan) were fixed in a $10 \%$ formalin

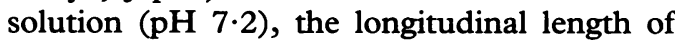
each colon was measured. The severity of ulcerative colitis in one longitudinal section of each colon was histologically graded on a scale from $0-4$ and expressed using the pathological index corresponding to the following modified standard scoring system ${ }^{12}: 0$, normal; 1 , focal inflammatory cell infiltration including polymorphonuclear leucocytes; 2, gland loss with
Enzymatic activities of thymidylate synthetase and thymidine kinase

Nine specimens of colonic tumours in group A, eight specimens of colonic tissue in group $B$, and seven specimens of colonic tissue in group $C$ were removed macroscopically, and separated into two parts, one for histological examination and the other for enzyme assay, and stored $-80^{\circ} \mathrm{C}$.

All specimens were homogenised with 10

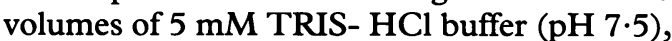
$0.1 \mathrm{mM}$ EDTA/1 mM mercaptoethanol/0.25 $M$ sucrose at $0^{\circ} \mathrm{C}$, The homogenate was centrifuged at $105000 \mathrm{~g}$ for one hour at $4^{\circ} \mathrm{C}$, and the supernatant was used as the crude enzyme preparation.

Assay of thymidylate synthetase (TS) activity TS activity was determined by the method of Dunlap et al. ${ }^{14}$ The assay mixture $(700 \mu \mathrm{l})$, consisting of a $0 \cdot 1 \mathrm{M}$ potassium phosphate buffer (pH 6.8), containing $5 \mathrm{mM} \mathrm{NaF}, 1 \mathrm{mM}$ dl, L5, 10-methylene-tetrahydrofolate, and $1 \mathrm{mM}$ $\left[{ }^{3}{ }^{3} \mathrm{H}\right] \mathrm{dUMP} \quad(10.6 \mathrm{Ci} / \mathrm{mmol}$; Amersham, UK), was incubated with the enzyme preparation at $37^{\circ} \mathrm{C}$ for 10 minutes. The reaction was stopped by adding $100 \mu \mathrm{l} \mathrm{HClO}_{4}(10 \%$; v/v). A volume of $200 \mu \mathrm{l}$ Norit A (8\%; w/v) was then added, and the mixture was centrifuged at $1500 \mathrm{~g}$ for 10 minutes at $0^{\circ} \mathrm{C}$. The supernatant $(200 \mu \mathrm{l})$ was added to $5 \mathrm{ml}$ of scintillant $(16.0 \mathrm{~g}$ PPO, 0.2 g POPOP, 1.01 Triton X-100, and 3.01 toluene), and the radioactivity was counted using a liquid scintillation counter (Packard Instrument, Downers Grove, IL). 
Induction of colorectal tumours in the chronic ulcerative colitis model

\begin{tabular}{|c|c|c|c|c|c|c|c|c|c|}
\hline & & \multirow[b]{2}{*}{$\begin{array}{l}\text { Number } \\
\text { of mice }\end{array}$} & \multicolumn{3}{|c|}{ Number of tumours } & \multicolumn{3}{|c|}{ Pathology score of UC } & \multirow{2}{*}{$\begin{array}{l}\text { Length of } \\
\text { colorectum } \\
(\mathrm{mm})\end{array}$} \\
\hline \multicolumn{2}{|c|}{ Group } & & $\begin{array}{l}\text { Right } \\
\text { colon }\end{array}$ & $\begin{array}{l}\text { Transverse } \\
\text { colon }\end{array}$ & $\begin{array}{l}\text { Left } \\
\text { colon }\end{array}$ & $\begin{array}{l}\text { Right } \\
\text { colon }\end{array}$ & $\begin{array}{l}\text { Transverse } \\
\text { colon }\end{array}$ & $\begin{array}{l}\text { Left } \\
\text { colon }\end{array}$ & \\
\hline $\begin{array}{l}\text { A } \\
\text { B } \\
\text { C } \\
\text { D }\end{array}$ & $\begin{array}{l}\text { AZM 3\% DSS } \\
\text { AZM DW } \\
\text { Saline 3\% DSS } \\
\text { Saline DW }\end{array}$ & $\begin{array}{l}14 \\
10 \\
11 \\
10\end{array}$ & $\begin{array}{l}0.0(0.0) \\
0.0(0.0) \\
0.0(0.0) \\
0.0(0.0)\end{array}$ & $\begin{array}{l}2.4(1.3)^{\star} \\
0.0(0.0) \\
0.0(0.0) \\
0.0(0.0)\end{array}$ & $\begin{array}{l}8 \cdot 1(3 \cdot 2) \dagger \\
0 \cdot 0(0 \cdot 0) \\
0 \cdot 0(0 \cdot 0) \\
0.0(0 \cdot 0)\end{array}$ & $\begin{array}{l}2.0(0.4) \\
0.2(0.1) \\
2.2(0.4) \\
0.2(0.1)\end{array}$ & $\begin{array}{l}2 \cdot 8(0 \cdot 6) \ddagger \\
0 \cdot 2(0 \cdot 1) \\
2 \cdot 9(0 \cdot 5) \ddagger \\
0 \cdot 1(0 \cdot 1)\end{array}$ & $\begin{array}{l}3.2(0.4) \oint \\
0.3(0.1) \\
3.5(0.5) \oint \| \\
0.3(0.1)\end{array}$ & $\begin{array}{c}103.5(4 \cdot 7) \\
114 \cdot 3(3.4) \\
98 \cdot 3(5 \cdot 6)^{\mathrm{a}} \\
114 \cdot 0(7 \cdot 7)\end{array}$ \\
\hline
\end{tabular}

^One of 34 tumours, submucosal-invasive adenocarcinomas; others, high-grade dysplasias. †Five of 113 tumours, submucosalinvasive adenocarcinomas; others, high-grade dysplasias. \#Significantly different $(\mathrm{p}<0.01)$ from the right colon. §Significantly different $(p<0.001)$ from the right colon. $\|$ Significantly different $(p<0.05)$ from the transverse colon. ๆSignificantly different $(p<0.001)$ from group B and $(p<0.01)$ from group D. aSignificantly different $(p<0.001)$ from groups B and D. Data shown as mean (SD). DW= distilled water.

Assay of thymidine kinase (TK) activity - TK activity was determined using the method of Taylor et al. ${ }^{15}$ The assay mixture $(200 \mu \mathrm{l})$, composed of $5 \mathrm{mM} \mathrm{MgCl}, 10 \mathrm{mM}$ ATP, $2 \mu \mathrm{M} \quad\left[6-{ }^{3} \mathrm{H}\right]$ thymidine $(21.0 \mathrm{Ci} / \mathrm{mmol}$; Amersham, UK), and a $0 \cdot 1 \mathrm{M}$ TRIS-HCl buffer ( $\mathrm{pH} 7 \cdot 5)$, was incubated with the enzyme preparation at $30^{\circ} \mathrm{C}$ for 15 minutes. Using a capillary tubing, $100 \mu \mathrm{l}$ sample were dropped on squares $\left(1.8 \times 1.8 \mathrm{~cm}^{2}\right)$ of DEAEcellulose paper (Toyo Filter, Tokyo, Japan) prior to washing with $1 \mathrm{mM}$ ammonium formate and $100 \%$ methanol. The washed paper was dried, inserted into vials containing scintillant $(25.0 \mathrm{~g} \mathrm{PPO}, 1.5 \mathrm{~g}$ POPOP, and 5.01 toluene), and the radioactivity was counted with a liquid scintillation counter.

Enzyme activities were expressed as means of duplicate assays in pmol or $\mathrm{fmol} / \mathrm{mg}$ protein/min. The protein content of the enzyme solution was measured by the method of Lowry et al, ${ }^{16}$ using bovine serum albumin as a standard.

\section{Statistical analysis}

Data are presented as means (SD). The statistical significance of differences between the control and experimental groups was determined for the severity of ulcerative colitis by the non-parametric Mann-Whitney $U$ test ${ }^{17}$ and for other parameters by the Student's $t$ test.

\section{Results}

Induction and histopathological characteristics of colorectal tumours arising in the chronic ulcerative colitis model

Group A mice that received azoxymethane pretreatment and repeated administrations of $3 \%$ DSS developed multiple tumours in the

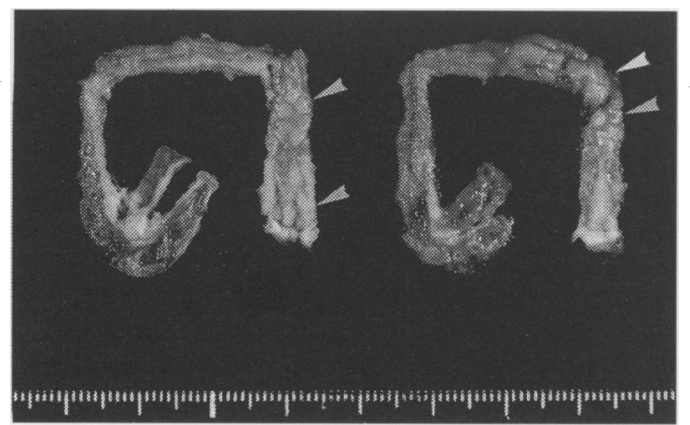

colorectal region. Polypoid or flat elevated lesions appeared in the transverse colon and left side of the large intestine, inclusive of the rectum, sigmoid, and descending colon (Table and Fig 2). Most tumours were papillotubular lesions with both severe cellular and structural atypia. Villous structures were also occasionally seen. Tumour cells occupied the entire layer of the colonic mucosa. Five of 113 tumours on the left side of the large intestine and one of 34 tumours in the transverse colon, were confirmed to be submucosal, invasive adenocarcinoma (Fig 3). All of the other tumours were histologically diagnosed as high grade dysplasias (Fig 4A). In vivo BrdU labelling showed that the proliferating zone was not limited to the base but extended to all areas of the tumorous tissue (Fig 4B). A regenerating zone was always found at the base of non-tumorous colonic mucosa. These signs were substantial enough to diagnose the pathological state as that of high grade dysplasia. Small, developed tumours tended to have an immature granuation tissue with inflammatory cell infiltration in the stroma (Fig 5). Regenerative mucosae also were frequently seen close to dysplasia lesions. No signs of tumour development were detected in control groups $\mathrm{B}, \mathrm{C}$, and $\mathrm{D}$.

Correlation between the severity of ulcerative colitis and development of colorectal tumours Pathological scores for ulcerative colitis showed remarkable changes in groups $\mathrm{A}$ and C. The mice that received repeated administrations of $3 \%$ DSS showed severe colitis regardless of the azoxymethane pretreatment.

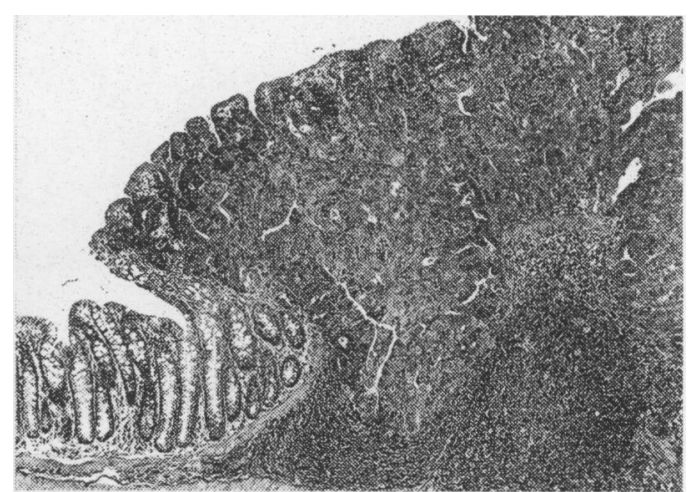

Figure 3: An elevated lesion with a papillotubular structure. Note submucosal invasion by tumour cells with lymph follicle formation (haematoxylin and eosin, original

magnification $\times 67$ ).
Figure 2: Induced colorectal tumours. Multiple elevated lesions are evident on the left side of the large intestine colon. The micronodules apparent in the caecum are lymph follicles. 
The length of the colorectum was significantly shorter $(p<0.001-0.01)$ than in control groups $B$ and $D$, resulting from inflammatory change (Table). Mice consistently showed blood in faeces, demonstrating that mucosal ulceration occurred with each administration cycle (seven days) of 3\% DSS (after the first administration of 3\% DSS, positive occult blood tests; nine of nine mice in group $\mathrm{A}$ and eight of eight mice in group C, respectively). After drinking distilled water for the following 14 days, occult blood tests generally revealed negative reactions (after the first cycle, positive occult blood tests; one of nine mice in group $A$ and 0 of eight mice in group C). Mice in groups A and C, killed 14 days after the third administration of $3 \%$ DSS, demonstrated multiple foci of gland loss with inflammatory cell infiltration but not many active mucosal erosions. Lesions were most severe on the left side of the large intestine followed by the transverse colon (Table). In addition to frequent appearance of regenerative mucosae in groups $\mathrm{A}$ and $\mathrm{C}$, which

\section{A}
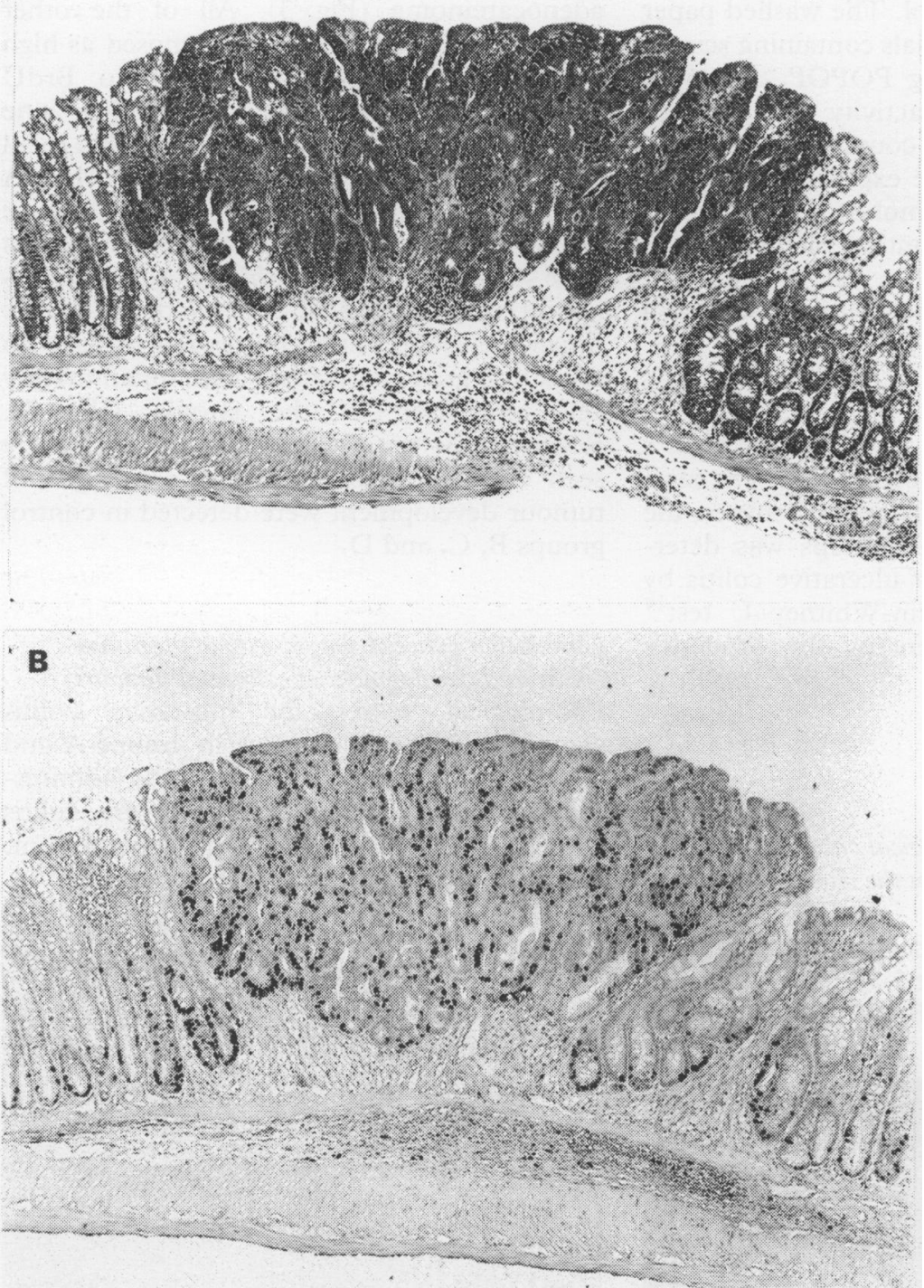

Figure 4: (A) A slightly elevated lesion diagnosed as high grade dysplasia demonstrating severe cellular and structural atypia (haematoxylin and eosin, original magnification $\times 67)$. $(B)$ In vivo BrdU labelling of tumour tissue (step histological section to $(A)$ ). BrdU labelled cells were distributed throughout the entire tumour tissue. In non-tumorous mucosa, BrdU labelled cells are limited to within the regenerating zone (enzyme immunohistochemistry with monoclonal anti-BrdU antibody, original magnification $\times 67)$.

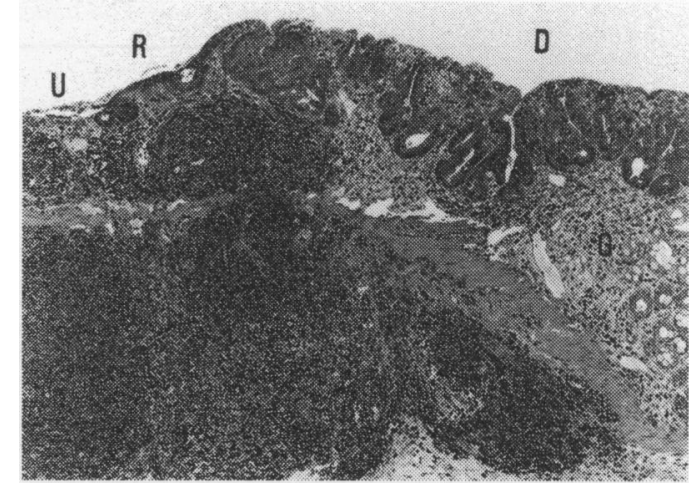

Figure 5: A flat elevated lesion of high grade dysplasia. The dysplasia lesion $(D)$ contains a granulation tissue $(G)$ with inflammatory cell infiltration at the bottom. Note erosion $(U)$ and regenerative mucosa $(R)$ close to dysplasia lesion. A large lymph follicle is localised around the muscularis mucosa (haematoxylin and eosin, original magnification $\times 100$ ).

received repeated administrations of $3 \%$ DSS, foci of regenerative atypia (Fig 6 ) in one longitudinal section of each colon were histologically counted as follows.

Group A: $0.6(0.6)$ (right colon), $1.8(1.5)$ (transverse colon), 2.0 (0.9) (left colon), respectively. Group C: $0 \cdot 2(0 \cdot 4)$ (right colon), $2 \cdot 2(2 \cdot 4)$ (transverse colon), $2 \cdot 4(1 \cdot 8)$ (left colon), respectively. Groups B and D: no foci of regenerative atypia in any part.

This correlated comparatively well with the locations of colorectal tumours that developed on the left side of the large intestine more than in the transverse colon $(p<0 \cdot 05)$. No tumours were found on the right side of the large intestine, where the severity of ulcerative colitis was mildest.

\section{$T S$ and TK activities in colorectal tumours}

TS activity was significantly increased $(p<0.01)$ in tissues bearing colorectal tumours (group A) than in the non-tumorous colorectal walls of control groups B and C (Fig 7). TK activity was also significantly higher $(p<0.05)$ in group A $(2 \cdot 23(1 \cdot 16) \mathrm{fmol} / \mathrm{mg}$ protein $/ \mathrm{min})$ than in control group $\mathrm{C}(1 \cdot 27(0 \cdot 26) \mathrm{fmol} / \mathrm{mg}$ protein/min).

\section{Discussion}

In this experiment, a single pretreatment with azoxymethane was sufficient to induce



Figure 6: Regenerative atypia with inflammatory granulation. It is frequently observed in groups $A$ and $C$, which received repeated administrations of $3 \%$ DSS

(haematoxylin and eosin, original magnification $\times 100$ ). 


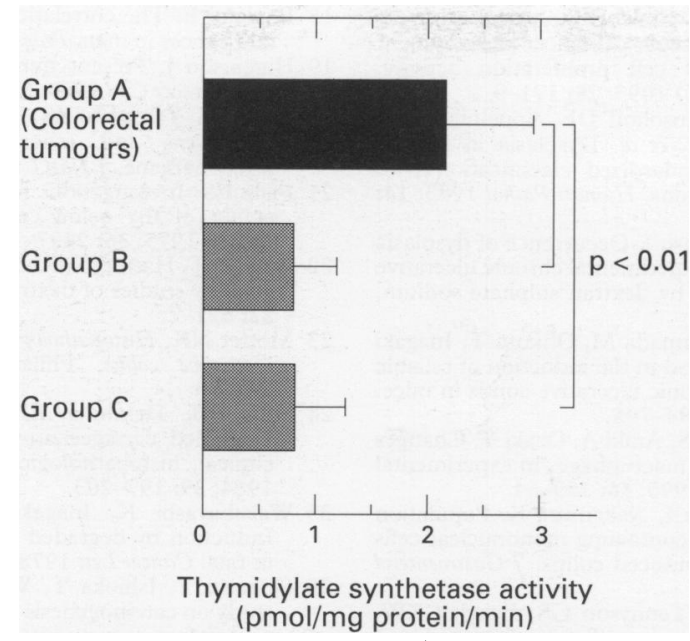

Figure 7: Thymidylate synthetase activity of induced tumour tissue and colonic mucosae of control groups $B$ and $C$ (see Fig 1). The enzyme activity was significantly higher $(p<0.01)$ in the colorectal tumours of group $A$ than in the colonic mucosae of groups $B$ and $C$. Values represent mean (SD).

multiple mucosal tumours in the colorectal wall within 77 days when combined with the stimulus of chronic ulcerative colitis. In line with the supposition that foods are contaminated with an extremely small quantity of carcinogenic substances in our life, ${ }^{18} 19$ a single pretreatment of azoxymethane was adopted in this experiment. Azoxymethane is known as a procarcinogen, which becomes an alkylating agent with carcinogenic activity after receiving metabolic activation in the host. ${ }^{2021}$ DSS has been found to be negative in the Ames test for mutagens. $^{22}$ Neither the azoxymethane pretreatment nor repeated administrations of $3 \%$ DSS induced any tumorous lesions in the colorectum. Therefore, clear synergism between the two agents was established.

With this experimental regimen, repeated administrations of 3\% DSS induced chronic ulcerative colitis dominantly on the left side of the large intestine followed by the transverse colon, this correlating well with the locations of tumours. Further, the frequent appearance of foci of regenerative atypia, also correlates well with both colitis and tumour development. Regenerative mucosae were seen in a focal distribution, close to the induced dysplasia lesions. A similar link has been described for neoplastic lesions seen in patients suffering from chronic ulcerative colitis. ${ }^{423}$ Summarising nine authors' reports, Mottet ${ }^{21}$ reported that approximately $71 \%$ of colon cancers in patients with ulcerative colitis developed on the left side of the large intestine and transverse colon. Further, in Japanese patients with ulcerative colitis, $19(82 \cdot 6 \%)$ of 23 colon cancers developed in these anatomical locations. ${ }^{4}$

The occurrence of colitis or tumours in the large intestine of rodents after longterm continuous administration of a sulphated polysaccharide has also been reported. Colitis can be induced by administration of degraded carrageenan, which is analogous to DSS. Carrageenan induced colitis in CF1 mice is more pronounced in the proximal colon forming severe dilatation and ulceration in the caecum and ascending colon. ${ }^{24}$ A $10 \%$ diet of degraded carrageenan in rats induces development of colorectal tumours, including squamous cell carcinomas, adenocarcinomas, anaplastic carcinomas, and adenomas. ${ }^{25} 26$ Also, adenomas and adenocarcinomas as well as papillomas were seen in rats fed a 5\% DSS supplemented diet for comparatively longterm periods of 102-215 days. ${ }^{27}$ Our group also reported that dysplasia or adenocarcinomas occur sporadically in hamsters after longterm (180 days) continuous administration of DSS. It was also reported that murine experimental colitis caused by weekly rectal instillations of 10 $\mathrm{mM}$ formyl-norleucyl-leucyl-phenylalanine in $6 \%$ dimethyl-sulphoxide increases the development of colonic cancer induced by multiple injections of 1,2-dimethylhydrazine. ${ }^{28}$ In comparison with these previous reports, however, the present experimental mouse model is rather short-term, and has the additional advantage of many similarities to the clinical case of tumorigenesis in ulcerative colitis.

With regard to the characteristics of the observed mucosal tumours, severe structural and cellular atypia pointed to a diagnosis of high grade dysplasia. According to established criteria, ${ }^{5}$ dysplasia includes intramucosal adenocarcinomas and neoplastic lesions showing borderline malignancy. Most of the present tumours corresponded to stage A of Astler and Coller's classification. ${ }^{29}$ Submucosal invasion by tumour cells was also evident in six of 147 lesions that developed during the comparatively short period of the experiment, although no distant metastases were found. The data thus provide evidence of a dysplasia-invasive adenocarcinoma sequence in the present experimental system. Our histological diagnosis was supported by the finding of diffuse labelling of tumour cells with BrdU throughout the colorectal mucosa. Further, both TS and TK showed significantly higher activities in mucosal tumours than in non-tumorous tissues. These enzymes, TS and TK, are responsible for de novo and the salvage synthesis of deoxy-thymidine monophosphate, respectively, and thus play an important part in supporting DNA synthesis under conditions of increased cell proliferation. ${ }^{30-32}$ Accordingly, a high proliferative activity of these neoplasms was confirmed.

In conclusion, this study featuring a single dose of carcinogen followed by induction of chronic ulcerative colitis achieved a high yield of tumours. This is the first such murine model, and it provides firm evidence that repeated mucosal necrosis and regeneration in ulcerative colitis facilitates the development of colorectal tumours.

The authors wish to thank Miss K Motoji, Mrs M Sakano, Mrs Y Numata, and Mrs K Hana for their technical assistance.

1 Hinton JM. Risk of malignant change in ulcerative colitis. Gut 1966; 7: 427-32

2 Dobbins WO. Dysplasia and malignancy in inflammatory bowel disease. Ann Rev Med 1984; 35: 33-48

3 Lennard-Jones JE, Melville DM, Morson BC, Ritchie JK, Williams CB. Precancer and cancer in extensive ulcerative colitis: findings among 401 patients over 22 years. Gut 1990; 31: 800-6.

4 Okayasu I, Fujiwara $M$, Takemura $T$, Toyoshima $H$, Takano T, Nakamura $K$. Development of colorectal 
cancer in ulcerative colitis: clinicopathological study of 347 patients and new concepts of cancer development from analysis of mucosal cell proliferation activity. Stomach and Intestine (Tokyo) 1993; 28: 171-9.

5 Riddell RH, Goldman H, Ransohoff DF, Appelman HD, Fenoglio CM, Haggitt RC, et al. Dysplasia in inflammatory bowel disease: standardized classification with provisional clinical applications. Human Pathol 1983; 14: provisional

6 Yamada M, Ohkusa T, Okayasu I. Occurrence of dysplasia and adenocarcinoma after experimental chronic ulcerative colitis in hamsters induced by dextran sulphate sodium. colitis in hamsters induce

7 Okayasu I, Hatakeyama S, Yamada M, Ohkusa T, Inagaki $Y$, Nakaya $R$. A novel method in the induction of reliable experimental acute and chronic ulcerative colitis in mice. Gastroenterology 1990; 98: 694-702.

8 Ohkusa T, Okayasu I, Tokoi S, Araki A, Ozaki Y. Changes in bacterial phagocytosis of macrophages in experimental ulcerative colitis. Digestion 1995; 56: 159-64.

9 Tokoi S, Ohkusa T, Okayasu I, Nakamura K. Population change of immunoglobulin-containing mononuclear cells in dextran sulfate sodium-induced colitis. $\mathcal{F}$ Gastroenterol 1996; 31: 182-8.

10 Dieleman LA, Ridwan BU, Tennyson GS, Beagley KW, Bucy RP, Elson CO. Dextran sulfate sodium-induced colitis occurs in severe combined imm
Gastroenterology 1994; 107: 1643-52.

11 Kanai I. Rinshokensahoteiyo. Tokyo: Kaneharashuppan (in Japanese), 1986: 180-3.

12 Onderdonk AB, Bartlett JG. The role of bacteria in experimental ulcerative colitis. Am $\mathcal{f}$ Clin Nutr 1979; 32: 258-65.

13 Shi Z-O, Itzkowitz SH, Kim YS. A comparison of three immunoperoxidase techniques for antigen detection in colorectal carcinoma tissues. $\mathcal{f}$ Histochem Cytochem 1988; 36: 317-22.

14 Dunlap RB, Harding NGL, Huennekens FM. Thymidylate synthetase from amethopterin-resistant Lactobacillus

15 Taylor AT, Stafford MA, Jones OW. Properties of thymidine kinase partially purified from human fetal adult tissues. $\mathcal{F}$ Biol Chem 1972; 247: 1930-5.

16 Lowry OH, Rosebrough NJ, Farr AL, Randall RJ. Protein measurement with the Folin Phenol reagent. $f$ Biol Chem 1959; 193: 265-75.

17 Siegel S. Nonparametric statistics. New York: McGraw-Hill, 1956: 1-312.
18 Boyland $\mathrm{E}$. The correlation of experimental carcinogenesis and cancer in man. Prog Exp Tumor Res 1967; 11: 222-34. 19 Higginson J. Present trends in cancer epidemiology. Proc Can Cancer Con 1969; 8: 40-75.

20 Ward JM, Yamamto RS, Brown CA. Pathology of intestinal neoplasms and other lesions in rats exposed to azoxymethane. $\mathcal{F}$ Natl Cancer Inst 1973; 51: 1029-39.

21 Fiala ES. Investigations into the metabolism and mode of action of the colon carcinogen 1,2-dimethylhydrazine. action of the colon carcin
Cancer 1975; 36: 2407-12.

22 Nagoya T, Hattori Y, Kobayashi F. Mutagenicity and cytogenicity studies of dextran sulfate. Pharmacometrics 1981; 22: $621-7$.

23 Mottet NK. Histopathologic spectrum of regional enteritis and ulcerative colitis. Philadelphia: WB Saunders, 1971: 217-35.

24 Fath RB, Deschner EE, Winawer SJ, Dworkin BM. Degraded carrageenan-induced colitis in CF1 mice. A clinical, histopathological and kinetic analysis. Digestion 1984; 29: 197-203.

25 Wakabayashi K, Inagaki T, Fujimoto Y, Fukuda Y. Induction by degraded carrageenan of colorectal tumors in rats. Cancer Lett 1978; 4: 171-6.

26 Oohashi Y, Ishioka T, Wakabayashi K, Kuwabara N. A study on carcinogenesis induced by degraded carrageenan study on carcinogenesis induced by degraded carrageenan arising from squamous metaplast

27 Hirono I, Kuhara K, Hosaka S, Tomizawa S, Golberg L. Induction of intestinal tumors in rats by dextran sulfate sodium. F Natl Cancer Inst 1981; 66: 579-83.

28 Chester JF, Gaissert HA, Ross JS, Malt RA, Weitzman SA. Colonic cancer induced by 1,2-dimethylhydrazine: promotion by experimental colitis. $B r \mathcal{F}$ Cancer 1989; 59: 704-5.

29 Astler VB, Coller FA. The significant prognosis of direct extension of carcinoma of the colon and rectum. Ann Surg 1954; 139: 846-51.

30 Herzfeld A, Legg MA, Greengard O. Human colon tumors: enzymic and histological characteristics. Cancer 1978; 42: enzymic

31 Sakamoto $S$, Iwama $T$, Tsukada $K$, Utsunomiya J, Kawasaki T, Okamoto R. Increased activity of thymidine kinase isozyme in human colon tumor. Carcinogenesis 1984; 5: 183-5.

32 Sakamoto S, Kuwa K, Tsukada K, Sagara T, Kasahara N, Okamoto R. Relative activities of thymidylate synthetase and thymidine kinase in 1,2-dimethylhydrazine induced colon carcinomas in rats. Carcinogenesis 1987; 8: 405-8. 